\title{
Praise greets accuracy of Leonid prediction
}

Washington

Last week's Leonid meteor storm, as well as being much more intense than last year's, marked the beginning of a new era in meteor forecasting. For the first time, researchers accurately predicted - to within minutes — when the two-day-long storm would peak.

The Leonids occur every November, when Earth's path crosses the tilted orbit of Comet Tempel-Tuttle. The display tends to be most dazzling at 33-year intervals, when the comet rounds the Sun and sheds a new layer of dust and grit to burn up in the Earth's atmosphere.

But forecasting the exact timing and intensity of any meteor shower (as measured by a standardized count known as the zenithal hourly rate, ZHR) is notoriously hard. Last year's Leonids, for example, surprised experts by peaking 16 hours earlier than expected.

Don Yeomans of the US space agency NASA's Jet Propulsion Laboratory, a veteran meteor prognosticator, wrote on his website last month that "like the weather, it is extremely difficult to predict the times and hourly rates of meteor showers".

Yet David Asher, of Armagh Observatory in Northern Ireland, and Rob McNaught, of the Australian National University in Canberra, nailed this year's Leonids peak almost exactly. Their prediction of 2:08 Universal Time on 18 November was off by five minutes at the most.

Yeomans, basing his forecast on historic Leonids observations, missed by 20 minutes. Most researchers declined to hazard such a precise guess.

Asher and McNaught use computers to model dust emission from the comet, taking into account the rate and speed of ejection, particle size and other factors. They then add repeated gravitational tugs from Jupiter and other planets and watch how the dust disperses.

According to their model, the thin ribbons of dust created during each 33-year passage retain their coherence for centuries. Whereas scientists previously had assumed these independent dust trails follow the same path as the comet, Asher and McNaught found that the orbits are slightly offset.

Knowing their positions can give very accurate peak times, as well as the age of the source meteors in the shower. This year, the Earth passed through a cloud of dust shed from Tempel-Tuttle in 1899. Next year we'll hit the outskirts of the 1733 trail and the 1866 trail.

Asher and McNaught credit several Russian researchers, including E. D. Kondrat'eva and E. A. Reznikov, who pioneered this method of meteor forecasting in the

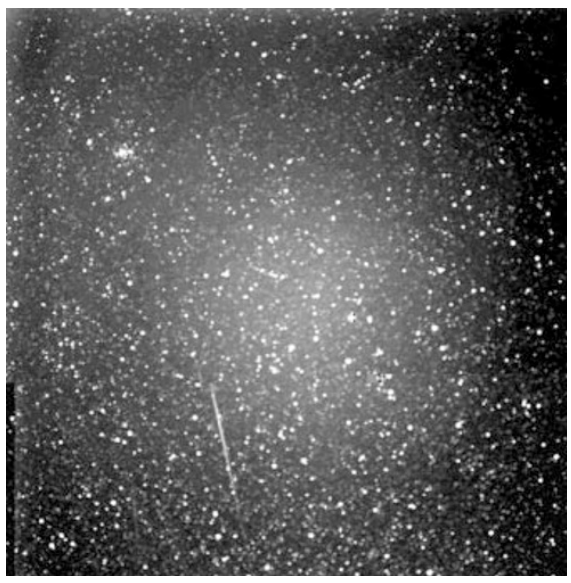

On cue: a Leonid meteor captured at 2:07 UT by the European Calar Alto observing team in Spain.

mid-1980s but went largely unnoticed by Western scientists.

Peter Brown of the University of Western Ontario, in London, Ontario, has obtained similar results with his own modelling of the Leonid stream. He also identified the 1899 cloud as the source of this year's shower.
The new modelling work has greatly advanced the art of meteor prediction, says Rainer Arlt of the Astrophysikalisches Institüt Potsdam, who is compiling this year's Leonids observations for the International Meteor Organization. "All of these models are working, no matter what the details of each model are. We're really able to follow the dynamics over 1,000 years without problems."

Predicting the meteor rate is a much tougher nut to crack, however. This year's ZHR was around 5,000, five to ten times the rate predicted by Asher and McNaught. Yeomans calls their forecast of the peak time "impressive", but says the real proof will come in 2001 and 2002.

Yeomans and other experts say the Leonids should have pretty much died down by then, while Asher and McNaught are calling for intense storms with ZHRs of 15,000 or more. "That's going way out on a limb," says Yeomans. "And if they get that right, I'll be the first to congratulate them on a major meteor-shower prediction breakthrough."

Tony Reichhardt

\section{Brookhaven leak reactor to close}

\section{Washington}

The US Department of Energy announced last week that the High Flux Beam Reactor at Brookhaven National Laboratory on Long Island, New York, is to close for good. The 34-year-old research reactor is the main source of cold neutrons for researchers in the United States

In announcing the reactor's closure, energy secretary Bill Richardson explained in a statement that "we need to focus our limited resources on productive research, rather than keeping the reactor in standby mode for an unknown length of time".

But Brookhaven researchers reacted furiously to the sudden decision, which appeared to bypass a lengthy process that had been under way to assess the environmental impact of reopening the reactor. It has been closed since early 1997, when a small leak of tritium from the pool that stores its spent fuel was detected in the ground beneath it (see Nature 386, $3-4$; 1997).

And although the eventual decision to close the reactor had been widely expected, neutron scientists were shocked that it was taken before the review process had been completed. "This has just become a circus," says Denis McWhan, associate director for basic energy sciences at Brookhaven. "We all

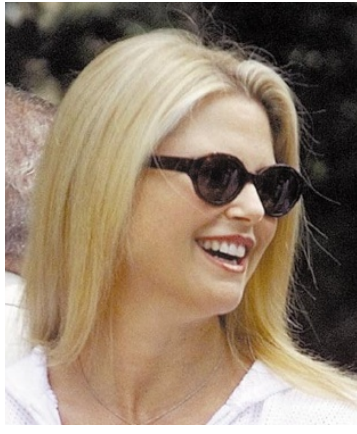

Model pressure? 'Supermodel' Brinkley expressed opposition.

Bring dismayed". He predicted it would make US researchers "second- if not third-class citizens compared to Western Europe and Japan".

Some researchers at Brookhaven linked the decision to a recent meeting between Richardson and two celebrated residents of Long Island, actor Alec Baldwin and 'supermodel' Christie Brinkley, who were representing a group opposing the reactor.

Richardson was in Turkey last week and unavailable for comment. But Ernie Moniz, the energy undersecretary, confirmed that such a meeting had taken place. "I believe he did meet with them. He got input from many different perspectives," he said.

According to Moniz, however, 


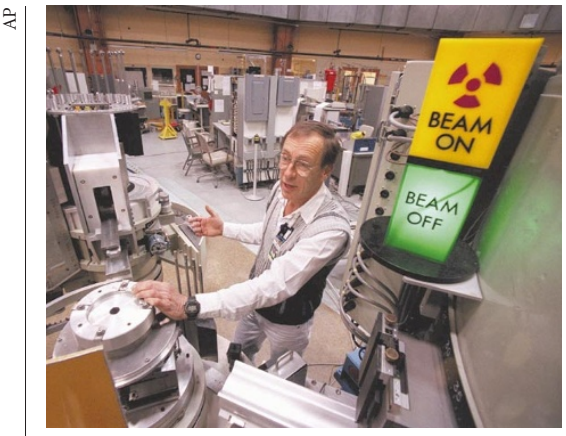

Off for good: the High Flux Beam Reactor.

- Richardson's decision was based on the advice of programme managers, who included Patricia Dehmer, senior staff official in charge of basic energy sciences, and Martha Krebs, head of the energy department's Office of Science. They recommended against continuing to spend \$20 million a year to keep the facility on standby.

"He got the recommendation of a termination, and on that day he made the decision," says Moniz. He points out that Brookhaven will remain one of very few laboratories housing two major scientific facilities, the Relativistic Heavy Ion Collider and the National Synchrotron Light Source.

Environmental groups have been pressuring the Department of Energy to close the reactor since the leak was discovered, even though the total amount of tritium discharged is less than that contained in an emergency exit sign in a cinema.

Opponents of the reactor were able to build on powerful anti-nuclear sentiment on Long Island. Construction of a nuclear power plant there was aborted after residents argued that the densely populated island could not be evacuated in an emergency.

The Department of Energy responded to the leak by firing the consortium of universities that had operated the laboratory. The new contractor had been making some progress in improving its relations with the laboratory's critics in the community (see Nature 400, 303; 1999).

But Michael Forbes, the local congressman, who recently switched from Republican to Democrat, has opposed the restarting of the reactor and has inserted language in appropriations bills for three years in a row expressly prohibiting it. Whatever Brinkley and Baldwin told Richardson, the energy secretary must have concluded that the department could no longer afford to spend an annual \$20 million maintaining an ageing facility that local politicians would not allow to reopen.

Colin Macilwain

\section{Science lobby 'ecstatic' after triumph in NIH budget battle}

\section{Washington}

The US National Institutes of Health (NIH) last week secured a 14.7 per cent increase in its budget for next year, achieving a remarkable triumph after an arduous congressional budget battle. The decision raises the biomedical agency's budget for the fiscal year 2000 to $\$ 17.9$ billion.

The House of Representatives and the Senate approved the increase just before adjourning for the year after weeks of struggle with the White House over budget priorities. The sum was part of a $\$ 385$ billion, 'omnibus' spending bill that combined five of the 13 bills funding the government.

Congress also last week approved a fiveyear extension to the research and development tax credit, which creates incentives for private industry to fund research projects.

The $\$ 2.3$ billion in new NIH funding, which keeps the agency on track for doubling its budget in five years starting this year, comes with two strings attached. The agency must wait until next 29 September, the end of the fiscal year, for $\$ 3$ billion of the overall budget. This is a budgetary device employed by Congress to allow it to appear to avoid spending Social Security revenues.

The NIH plans to handle the problem with 'split funding' — giving investigators part of their award at the time it is granted, and paying the remainder at the end of the fiscal year. Advocates see this as a big improvement on an earlier proposal that would have delayed $\$ 7.5$ billion in $\mathrm{NIH}$ funding to late September, and forced the postponement of new grants until then.

The $\$ 3$ billion deferral is "something that we can cope with," says David Kaufman, president of the Federation of American Societies for Experimental Biology (FASEB) and a professor of pathology at the University of North Carolina at Chapel Hill.

In addition, the NIH, like other federal agencies, is expected to be subject to a 3.8 per cent across-the-board spending cut insisted on by Republicans as a symbol of fiscal austerity. This would slice $\$ 68$ million from NIH's budget, lowering its effective increase to $\$ 2.23$ billion, or 14.3 per cent. But the loss is not definite, as the bill allows the president to exempt certain agencies from cuts.

Such provisos were insufficient to dampen the enthusiastic reaction of research advocates. They said last week that the NIH had pulled off a tremendous coup in wresting such a large increase from a budget maelstrom that saw Republicans fighting to find budget savings in all conceivable areas.

"It's an outstanding outcome. We're just ecstatic," says Tim Leshan, director of public policy at the American Society for Cell Biology. Considering that there were those in Congress who felt that the increase "was just too much too fast," the new money is "a tremendous victory," adds Mike Stephens, a FASEB lobbyist.

The bill includes a $\$ 45$ million increase in the NIH budget for the construction of extramural facilities, taking it to $\$ 75$ million. University administrators and NIH officials had been complaining that the agency's budget was insufficient for what they describe as the decaying infrastructure of US biomedical research facilities (Nature 399, $621 ; 1999$.

Meredith Wadman

\section{Hughes institute unveils top team}

\section{Washington}

The Howard Hughes Medical Institute (HHMI), the largest biomedical research charity in the United States, has appointed a management team that is expected to shake up the institute's portfolio in the new year.

Gerry Rubin, a geneticist at the University of California at Berkeley, will join the institute on 1 January as vice-president for biomedical research. He will team up with David Clayton, who will become vicepresident for science development.

The two appointments were announced last week by Tom Cech, the University of Colorado Nobel laureate who takes over as president of the HHMI in January. Cech said the appointments to replace Max Cowan, the institute's retiring scientific director, signalled the expanding scope of its activities.

"Max is irreplaceable, so we've decided to divide things up a bit differently," says Cech, adding that the decision reflects the continuing expansion of the institute's portfolio. "If we just planned to maintain what we have, we wouldn't need two people."

The HHMI's annual expenditure has grown rapidly in recent years, from around $\$ 300$ million in 1994 to more than $\$ 500$ million last year, as the stock-market boom has fed an endowment now worth some $\$ 10$ billion. Four-fifths of the expenditure supports an elite of 300 salaried investigators - all biomedical scientists at US universities with the rest distributed as grants for under- 